be very useful in case 2), its structural rigidity and, in case of malignant disease, resistance to infiltrative growth by tumour. Disadvantages include a greater tendency to displace, and the risk of obstruction by dried airway secretions. Gianturco $\mathrm{Z}$ stents do not move and probably do not induce drying of secretions; furthermore, they allow airflow through the stent itself - for example, when placed over the right upper lobe bronchus. Both types of stents probably could have been used in our patients. We preferred the silicone Dumon stents because of their structural rigidity, the ease by which they can be removed, and our greater experience with them.

We conclude that an endoscopically inserted silicone endoprosthesis may be a valid alternative to surgery for tracheal obstruction due to intrathoracic goitre in patients in whom surgery represents an unacceptable risk.

1 Hetzel MR, Smith SGT. Endoscopic palliation of tracheobronchial malignancies. Thorax 1991;46 325-33.

2 Colt HG, Dumon JF. Tracheobronchial stents: indications and applications. Lung Cancer 1993;9:301-6.

3 Dumon JF, Corsini A. Cicatriceal tracheostenosis. In: Bnnchoscopic Laser Resection Manual. Marseilles, France: 1989: 137.

4 Ingbar DH. The respiratory system in thyrotoxicosis. In: Braverman LE, Otiger RD, eds. The thymid. 6th edn Braverman LE, Otiger RD, eds. The

5 Calcaterra TC, Maceri DR. Aerodigestive dysfunction secondary to thyroid tumors. Laryngoscope 1981;91:701-7. 6 Alfonso A, Christoudias A, Amarrudin Q. Tracheal or eosophagal compression due to benign thyroid disease. Am f Surg 1981;142:350-4.

7 Karbowitz SR, Edelman LB, Nath S. Spectrum of advanced upper airway obstruction due to goitres. Chest 1985;87: 18-21.

8 Simonds AK, Dirving JD, Clarke SW, Dick R. Use of expandable metal stents in the treatment of bronchial obstruction. Thorax 1989;44:680-1.

\section{Massive haemothorax secondary to angiosarcoma}

\author{
A J McCleary
}

Cardiothoracic Surgery, Killingbeck

Hospital, Leeds, UK A J McCleary

Reprint requests to: A J McCleary,

10 Skippon Terrace,

Leeds LS14 3HA, UK

Received 5 August 1993 Returned to authors 15 October 1993

Revised version received

10 November 1993

Accepted for publication

5 January 1994

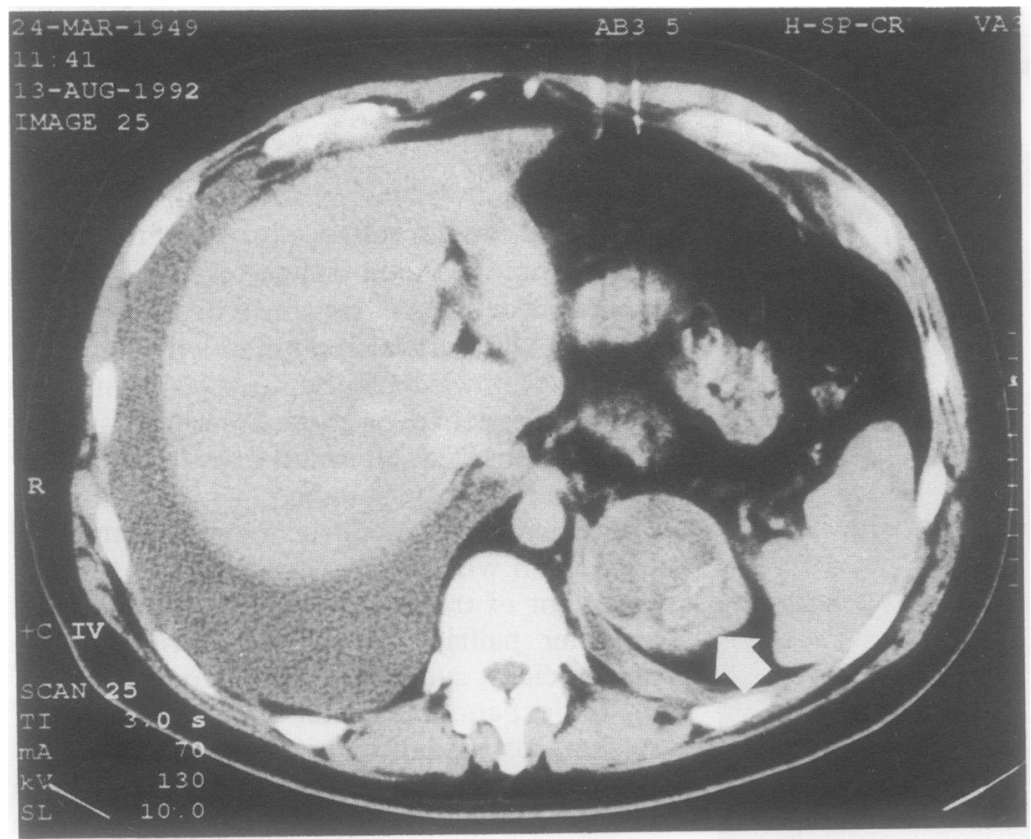

Figure 1 Computed tomographic scan of the abdomen showing a large mass in the left adrenal gland and right sided haemothorax.

\begin{abstract}
A patient who presented with recurrent haemoptyses was found to have an angiosarcoma of the adrenal gland which disseminated throughout the pleural space.
\end{abstract}

(Thorax 1994;49:1036-1037) abdomen revealed a left adrenal mass measuring $5 \times 4 \times 4 \mathrm{~cm}$ (fig 1 ).

A further 20 litres of blood were drained over the following five days. Clotting screens were normal and the adrenal tumour appeared to be non-functioning (urinary levels of 17ketosteroids and vanillylmandelic acid were normal). Pulmonary angiography and selective angiography of the intercostal arteries failed to demonstrate a definite bleeding point.

On the sixth day adrenalectomy and exploratory thoracotomy were performed. The adrenal mass was a well circumscribed cystic lesion filled with organising blood clot. Two litres of blood were removed from the left hemithorax to reveal visceral and parietal pleura covered in organising blood clot and studded with multiple haemorrhagic cysts $5-30 \mathrm{~mm}$ in diameter. The lung parenchyma appeared to be normal. Frozen sections of the lesions were reported as angiosarcoma. Bleeding was controlled and the chest closed.

Postoperatively the patient had a dense right sided hemiplegia. However, he remained stable 


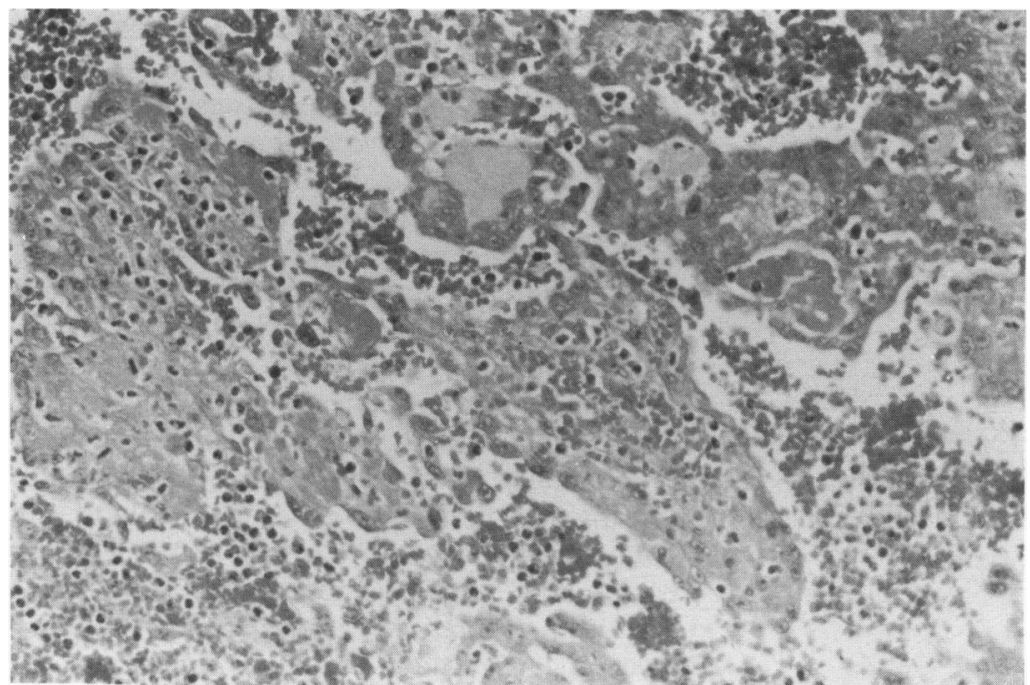

Figure 2 Photomicrograph of section through the adrenal tumour. The typical appearances of an angiosarcoma are demonstrated with vascular channels lined by pleomorphic cells that are either spindle shaped or epithelioid forming papillae and cords. Stain: haematoxylin and eosin. Original magnification $\times 100$ reduced to $66 \%$ on origination.
Primary angiosarcomas of the adrenal gland or lung are exceptionally rare with only two convincing reported cases of primary adrenal ${ }^{12}$ and three of lung origin..$^{3-5}$ There are further reports of adrenal involvement in disseminated disease $^{6}$ and angiosarcomas frequently metastasise to the lungs.

In the case described here it is unclear where the tumour originated. The single large adrenal tumour with multiple pleural deposits tends to suggest an adrenal primary. Indeed, the pattern of multiple small haemorrhagic nodules studding the pleura is common in metastatic disease. However, it is also described in two of the three cases of primary lung disease. ${ }^{34}$

The histological diagnosis of angiosarcoma is often difficult. The characteristic features are well described by Kareti et al. ${ }^{1}$ Demonstration of the endothelial markers Factor VIII related antigen and Ulex europaeus agglutinin I strongly support the diagnosis. Thrombomodulin is said to be a more sensitive and specific marker. ${ }^{7}$

The prognosis of angiosarcoma is poor. Forty cases of cardiac angiosarcoma had a mean survival of nine months. ${ }^{6}$ Cutaneous angiosarcoma has a better prognosis with one series reporting a five year survival of $12 \%{ }^{8}$ In isolated cases prolonged survival has been reported following radical surgery, ${ }^{1}$ radical radiotherapy, ${ }^{8}$ and a combination of surgery, radiotherapy and chemotherapy. ${ }^{6}$ Interferon alpha-2a induced regression in a child. ${ }^{9}$

Death is often related to pulmonary involvement. In a series of six patients with cardiac angiosarcoma five died as a consequence of lung metastases. ${ }^{6}$ Lung deposits may cause respiratory failure by a combination of local infiltration, intrapulmonary, and intrapleural haemorrhage. $^{35}$ In the case reports where patients have presented with respiratory symptoms, survival has been only a matter of weeks. ${ }^{3-5}$ hibited the typical appearance of angiosarcoma (fig 2). Along with the classic appearance, positive staining for Factor VIII related antigen and Ulex europaeus agglutinin I confirmed the diagnosis of angiosarcoma.

The lung parenchyma was normal and no other deposits of tumour were found. The brain was found to have multiple infarcts that were thought to have been secondary to extreme fluctuations in blood pressure perioperatively.

\section{Discussion}

Angiosarcoma is a rare tumour that occurs in skin, bone, breast, and visceral organs, especially the liver. It is associated with exposure to vinyl chloride, thorotrast, arsenic, radiotherapy, and to chronic post mastectomy lymphoedema.
1 Kareti LR, Katlin S, Siew S, Blauvelt A. Angiosarcoma of the adrenal gland Anch Pathol Lab Med 1988;112:1163-5. of adrenal gland presenting as a paraneoplastic syndrom: case report. F Urol 1991;146:1101-3.

3 Case records of the Massachusetts General Hospital, case \# 40191. N Engl f Med 1954;250:837-43.

4 Tralka GA, Katz S. Hemangioendothelioma of the lung. Rev Respir Dis 1963;87:107-15.

5 Spragg RG, Wolf PL, Haghighi P, Abraham JL, Astarita RW. Angiosarcoma of the lung with fatal pulmonary haemorrhage. Am $₹$ Med 1983;74:1072-6.

6 Herrman MA, Shankermann RA, Edwards WD, Shub C, Schaff HV. Primary cardiac angiosarcoma: a clinicopathological study of six cases. $\boldsymbol{f}$ Thorac Cardiovasc Surg 1992;103:655-64

7 Yonezawa S, Maruyama I, Sakae K, Igata A, Marjerus PW, Sato $\mathrm{E}$. Thrombomodulin as a marker for vascular tumours. Am $\mathcal{F}$ Clin Pathol 1987;88:405-11.

8 Holden CA, Spittle MF, Jones EW. Angiosarcoma of the face and scalp: prognosis and treatment. Cancer 1987;59: 1046-57.

9 White CW, Wolf SJ, Korones DN, Sondheim HM, Tosi MF, Yu Akie. Treatment of childrood angiomatous diseases with recombinant interferon alfa-2a. $\mathcal{F}$ Pediatr 1991;118:59-66.
2 Bosco PJ, Silverman ML, Zinman LM. Primary angiosarcoma 